\title{
Usefulness of diaphragmatic ultrasound in guiding tracheal extubation in pediatric surgery
}

\author{
${ }^{1} \mathrm{M}$. V. Pesce, ${ }^{1} \mathrm{C}$. Babetto, ${ }^{1} \mathrm{~F}$. Pugliese, ${ }^{1} \mathrm{~F}$. Fattorini, ${ }^{2} \mathrm{D}$. Galante, ${ }^{1} \mathrm{M} . \mathrm{V}$. Ranieri \\ 1Department of Anesthesia and Intensive Care, University La Sapienza, Rome, Italy \\ ${ }^{2}$ Department of Anesthesia and Intensive Care, University Hospital Ospedali Riuniti of \\ Foggia, Italy
}

\section{Background}

The optimal timing for tracheal extubation is important, specially in children, to prevent perioperative respiratory adverse events, such as laryngospasm, bronchospasm, persistent coughing, airway obstruction, desaturation. The recovery of diaphragmatic function is the main factor for successful extubation from mechanical ventilation while the sonografic evaluation has been conducted mostly in intensive care units. In this study we evaluate if the assessment of diaphragmatic mobility can be useful in identifying the exact moment of extubation in operating room.

\section{Materials and methods}

A total of 40 patients aged between 3 and 6 years with no comorbidities, undergoing minor abdominal surgery, were studied and divided into two homogeneous groups. General anesthesia was conducted with sevoflurane and fentanyl in refracted bolus, without use of myorelaxants. In first group we proceeded to extubation following standard clinical evaluation and in the second one we evaluated also diaphragm function. B and $\mathrm{M}$-mode sonografy was used to mesure the excursion (DE) and thickness, expressed as diaphragmatic thickening fraction (DTF), of the right hemidiaphragm (using the liver as acoustic window). Our target values were $\mathrm{DE}>4 \mathrm{~mm}$ and $\mathrm{DTF}>30 \%$. We recorded as ventilatory parameters, at the end of surgery and at the resumption of spontaneus breathing, the end tidal sevoflourane, volume tidal, end tidal $\mathrm{CO} 2$, respiratory rate and oxygen saturation.

\section{Results}

In the second group the extubation was performed only after the achievement of target values of DE and DFT and in $60 \%$ of cases it occurred after the normalization of ventilatory parameters. We recorded a reduced incidence of early post-extubation complications in group 2 ( $0 \%$ vs $5 \%$ in group 1 that consisted in episodes of desaturation resolved with oxygen administration and persistent coughing).
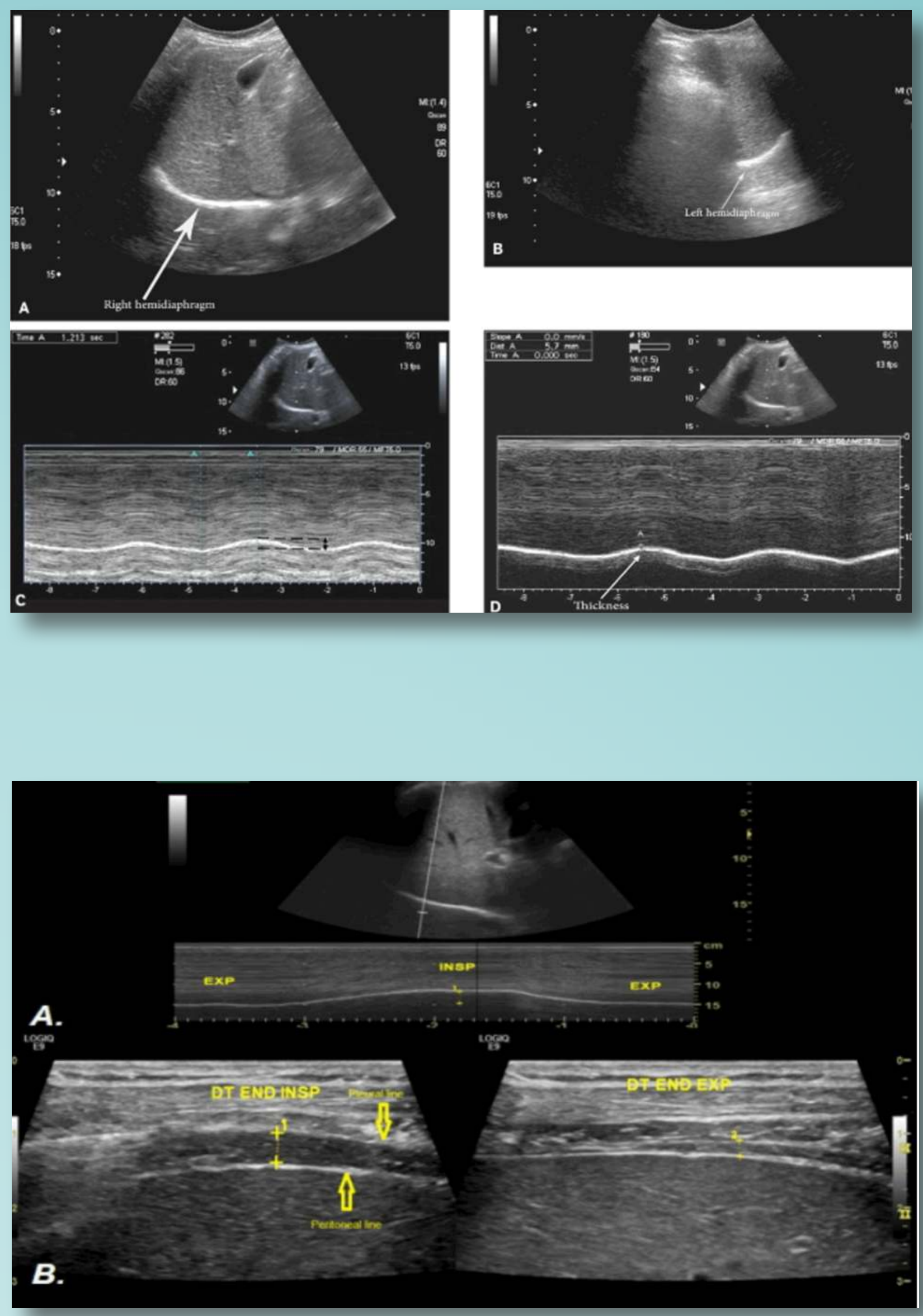

\section{Conclusions}

Our study showed that, the necessity of a deep extubation in children could, in opposite, cause a premature one due to reduced diaphragmatic activity. Ultrasound monitoring represents an effective method, associate with clinical valutation, to determine the resumption of diaphragmatic function following a general anesthesia.

\section{Euroanaesthesia} THE EUROPEAN ANAESTHESIOLOGY CONGRESS 